\title{
La normativización del cuerpo femenino en la Edad Moderna: el vestido y la virginidad
}

\author{
Isabel Pérez Molina \\ Centre de Recerca de Dones «Duoda» (Universidad de Barcelona)
}

\begin{abstract}
RESUMEN
ABSTRACT

La legislación de la Edad Moderna, como parte del discurso dominante, situó a las mujeres en una posición de inferioridad con respecto a los hombres. Esta discriminación se manifestó incluso en las normativas impuestas al cuerpo femenino.

Aqui se analizan dos aspectos de esas normativas: el referido a la necesidad de cubrir el cuerpo de una determinada manera y el que concierne a la virginidad, cuya exigencia es consecuencia del Law in Early Modern Times, as a part of the the prevailing discourse, put women in a position of inferiority in relation to men. This discrimination became apparent even in the rules imposed on women's body. The article analyses two aspects of these rules: the exigence for women to cover their body in a concrete way and the exigence of virginity, as a consequence of men's control of feminine sexuality.
\end{abstract}

control de la sexualidad femenina por parte del hombre.

La legislación moderna, como parte del discurso dominante, situó a las mujeres en una posición de inferioridad con respecto a los hombres, encuadrándolas en una categoría social específica con particularidades propias y subordinadas. Para justificar esta inferioridad jurídica y social se diseñó un cuerpo ideológico que, de manera más o menos burda o más o menos sofisticada, intentaba demostrar dicha inferioridad física y moral femenina. Las mujeres eran, de acuerdo con los parámetros del discurso dominante, hombres imperfectos y como tales, inferiores y débiles tanto a nivel físico como a nivel moral e intelectual. Así, el cuerpo ideológico inventó normas y actitudes hacia el cuerpo de las mujeres.

La conceptualización de debilidad e inferioridad como características inherentes a las mujeres fue reforzado continuamente por dicho discurso dominante. Las mujeres eran culpables de todos los males del mundo, originados a partir del pecado 
de Eva - una versión cristiana de la caja de Pandora - y todavía lo eran más al no someterse obediente y sumisamente a los roles que se les asignaban. Los hombres crearon para las mujeres unos "grupos sociales" o categorías diferentes a las de los hombres aunque superpuestas y subordinadas a éstas, imponiendo, al tiempo, la subordinación y dependencia de las mujeres. Fueron divididas en "honestas" y «deshonestas», en «buenas» y "malas». Esta clasificación de las mujeres por el simple hecho de serlo dependía de la naturaleza específica de sus relaciones, particularmente sexuales, con los hombres. La Iglesia y los moralistas de la época se encargaron de dar forma erudita a esta dicotomía ideológica en sus obras'.

Esta clasificación se ligó con el concepto del honor, que enmarcó la vida de las mujeres a lo largo de la historia, y particularmente durante la Edad Moderna. El honor ligado a la honra o conducta sexual de las mujeres es fundamental para las sociedades en las que la propiedad se transmite por vía patrilineal. En una sociedad en la cual las mujeres se convierten en una mercancia de intercambio para hacer posible la transmisión de riqueza entre hombres, la función reproductora de las mujeres y el control de esta función, o lo que es lo mismo, el control de la sexualidad de las mujeres por parte de los hombres, se convierte en un valor esencial para el mantenimiento de la estructura social además de ser el principio estructurante de las relaciones entre los sexos ${ }^{2}$. La cuestión de la honestidad estará presente en todos los apartados de la vida cotidiana de las mujeres, puesto que todas sus acciones serán juzgadas según la pauta del honor, ya que se utilizará para justificar las limitaciones a su capacidad jurídica, para limitar su posible acceso al trabajo o para acomodar a estas pautas el modelo educativo para las niñas.

Sin embargo, el honor y la honra tienen sobre todo relación con el cuerpo, el cubrimiento del cuerpo, la decencia, la atribución de pureza /castidad o impureza a una mujer según sea su comportamiento sexual. Por ello los códigos de honor se reflejan en la ley, parte del cuerpo simbólico, del discurso dominante. En este artículo analizaremos dos aspectos referentes al cuerpo femenino, su adorno y la virginidad, teniendo en cuenta que, según asevera Michel Certeau, por una parte, las inscripciones jurídicas constituyen el cuerpo como parte del orden social o colectivo, estructurando la amplia categoría de subjetividad requerida en épocas concretas. Por otra parte, también es necesario tener en consideración que, la apariencia autorizada de lo «real», es decir, su representación, lo que hace es camuflar la práctica que realmente está detrás del hecho en si mismo ${ }^{3}$.

1 Este tema lo trato más extensamente en los capítulos 3 a! 6 de I. PéREZ Molina, Las mujeres ante la ley en la Cataluña moderna, Granada, Ediciones de la Universidad de Granada, Colección Feminae, 1997.

2 Sobre el honor y el control de la sexualidad femenina, ver: C. PATEMAN, The Sexual Contract, Cambridge, Polite Press, 1988, pp. 189, 200-210; y M. PALAzzI, «Female Solitude and Patrilineage: Unmarried Women and Widows during the Eighteenth and Nineteenth Centuries", Journal of Family History, vol. 15, n. ${ }^{\circ} 4(1990)$, p. 445.

${ }^{3}$ M. CerTEAU, “History: Science and Fiction", en Heterologies: Discourse on the Other, Minneapolis, University of Minnesota Press, 1994, p. 203. Ver, también: E. Grosz, Volatile Bodies: Toward a Corporeal Feminism, Sidney, Allen \& Unwin, 1994, p.118. 


\section{EL RECUBRIMIENTO DEL CUERPO}

La preocupación sobre el adorno del cuerpo femenino, léase vestido, joyas y otros adornos, aparece ya en época romana. Tertuliano, que vivió entre los siglos II y III, en De cultu feminarum, afirma que los adornos son apropiados para la mujer, Eva, que está condenada y está muerta, para tapar su muerte e ir ataviada como para dar esplendor a su funeral. Los tratados medievales De ornatu también tratan este tema, así como otros textos, entre ellos las leyes que trataremos a continuación ${ }^{4}$.

La historiadora medievalista Milagros Rivera se ha detenido a estudiar el sentido del adorno femenino. Según dicha autora, la compresión de la polémica sobre por qué o para quién se han adornado las mujeres se ve dificultada si no se entiende que las mujeres han vivido en una sociedad patriarcal que tiene como una de sus instituciones básicas la heterosexualidad obligatoria ${ }^{5}$. La condena por parte del discurso patriarcal del adorno de las mujeres o bien al contrario, conformar el adorno como algo que las mujeres hacen para atraer a los hombres, llevándolo muchas veces a su exageración y a la manipulación, se inscribiría dentro de estos parámetros que, a través de la institución de la heterosexualidad obligatoria, reprimen actitudes o acciones y manipulan su significado último.

Siguiendo esta línea argumental, la práctica del adorno del cuerpo femenino formaría en su sentido primigenio parte del orden materno, comunicando a las mujeres con el origen femenino de la vida humana desde la carne, la vinculación con la madre. Ello independientemente de que durante el Renacimiento, algunas mujeres, opinaran sobre el tema, a favor y en contra del adorno femenino, entre ellas la humanista Laura Ceretta, quién estimaba que las mujeres deberían ocuparse más del adorno de la mente que del cuerpo ${ }^{6}$.

Durante los períodos medieval y moderno se promulgaron en toda Europa leyes suntuarias sobre el lujo y el vestido. Algunas de ellas tenían un claro sentido económico de cara a la protección de la industria local y de cara a prevenir la dilapidación de las riquezas por los excesivos gastos en este tipo de cosas por apariencia de estatus. Estas leyes se referian tanto a hombres como a mujeres y regulaban también el lujo de carruajes y cómo habían de vestir los servidores. Sin embargo, una parte sustancial de esta normativa se refería especificamente a las mujeres, y su significado iba más allá del estrictamente económico, inscribiéndose en el marco del control sobre el cuerpo de las mujeres y la demarcación de las categorías creadas por la sociedad patriarcal para ellas.

4 Tertuliano, On the Apparel of Women, parte 4, libro 1, en A. Roberts, J. Donaloson (Ed.). Ante-Nicene Fathers. Third ano Fourth Centuries, Wm. B. Eermans Publishing Co, 1988 y M. RIvERA GARRETAS, Nombrar el mundo en femenino, Barcelona, Icaria, 1994, pp. 133, 214.

5 Rivera Garaetas, Nombrar..., pp. 133, 213.

6 Ibidem, pp. 133-136; y M. L. King; A Rabil (eds.), Her Immaculate Hand, Medieval \& Renaissance Texts \& Studies, Binghampton, Nueva York, 1992. 
Las normas que podian regular diferencias sociales entre las personas, las regulaban también de forma diferencial según la honestidad de las mujeres, es decir, haciendo clara la distinción entre las «buenas» $u$ «honorables» y las «malas», entre las prostitutas y el resto de las mujeres. El pudor hacía que se regulase, por ejemplo, la medida del escote. No atraer indecorosamente la atención con el vestido, síntoma de inmoralidad sexual, o no malgastar los dineros del marido, a lo cual se presuponía eran propensas las mujeres, eran algunos objetivos de estas leyes. Las mujeres de las ciudades vestían de una forma que los hombres de leyes y los sacerdotes consideraron impropia de las mujeres honestas y relacionaron la forma más o menos sugerente de vestir con la propensión a tener un comportamiento sexual reprobable para las mujeres en esa época, léase adulterio, relaciones sexuales no protegidas por el matrimonio, etc. Paradójicamente, las mujeres «recatadas» o pudorosas tenían menos probabilidades de casarse a no ser que tuvieran una buena dote ${ }^{7}$.

En los territorios de la monarquía hispánica, tanto la legislación catalana como la castellana promueven este tipo de leyes, si bien en Cataluña, durante la Edad Media, serán sobre todo las ordenanzas de las ciudades las que se encargarán de ello. En cuanto a la legislación general, la ley castellana contempla este tema más ampliamente, con toda una serie de disposiciones que aparecen recogidas en la Novísima Recopilación.

En las ordenanzas municipales de la ciudad de Barcelona estudiadas por Teresa Vinyoles para las postrimerias de la Edad Media aparecen bandos prohibiendo el lujo en los vestidos y otras disposiciones de este tipo. Las primeras ordenanzas sobre el tema están fechadas en 1344, y en ellas se prohíbe a hombres y mujeres llevar telas bordadas y estampadas, ornamentos de plata y oro, etc. Se delimita lo que han de vestir las mujeres incluso en su casa, pues no pueden llevar ni en su casa ni en la calle mantellinas o zamarras que no sean de lana. Tampoco pueden llevar pieles, plumas y otros ornamentos, puntas en los velos, capas, etc., y se prohiben los escotes desmesurados, entre otras medidas. Este tipo de órdenes se van repitiendo, incluyendo, por ejemplo, la prohibición de llevar tocados de estilo castellano, más lujosos que los catalanes. Las niñas menores de cinco años y las prostitutas se contemplarían como las únicas excepciones a la regla ${ }^{8}$.

Curiosamente, cabe destacar como el uso de las mismas categorias aplicadas a las mujeres, es decir, su clasificación en honestas y deshonestas, se traduce en normativas distintas, e incluso contradictorias, en Castilla o en Cataluña. En Cataluña, a diferencia de lo que veremos en la legislación castellana, las prostitutas o mujeres «viles" pueden vestir como quieran, pero no pueden ir cubiertas ni llevar manto o capa como las damas. Vemos diferencias en el vestido según el grado de

7 B. S. Anderson y J. P. Zinsser, A History of Their Own, Londres, Penguin Books, 1988, vol. I, p. 434; y T. M. VINYOLES, "La mujer Bajomedieval a través de las Ordenanzas Municipales de Barcelona", en DD.AA., Las mujeres medievales y su ámbito jurídico, Actas de las II Jornadas de Investigación Interdisciplinaria, Madrid, Universidad Antónoma de Madrid, 1983, pp. 140-141.

${ }^{B}$ VINYOLES, "La mujer...", pp. 138-144. 
honestidad que se les atribuye, según el estado civil, y según el estatus social. Las mujeres casadas llevan la cabeza cubierta con velos. Las viudas van vestidas de negro. A veces, parece que este color se pone tan de moda, que las autoridades restringen el uso a familiares próximos de la persona fallecida, por el coste de este vestuario y para que la ciudad no parezca una procesión funeraria. En este sentido se manifiesta la Constitución "Per quant en los casos", recogida en las Constituciones de Cataluña. También en el sentido de restringir el lujo del vestido, incluyendo "paños" (telas) y "fajas forasteras", bajo pena de 10 libras y ropa decomisada, se manifiesta la Constitución "Considerant los grans", promulgada por Felipe $\mathrm{V}$ el año $1702^{9}$.

Por lo que se refiere a la legislación castellana, existen disposiciones similares prohibiendo el lujo en los vestidos, y las telas de o con oro y plata, aunque existen diferencias, como se ha visto, particularmente con respecto a la postura acerca de las prostitutas, que resulta más restrictiva que hacia el resto de las mujeres. En esta dirección se sitúa una ley fechada en 1534, posteriormente ratificada por una pragmática en el año 1623, que obliga: «...que las mugeres, que públicamente son malas, y ganan por ello, no puedan traer ni traigan oro, ni perlas ni seda, so pena de perder la ropa de seda, y con ella lo que traxeren, y en cuento a los bordados y guarniciones de oro, entendiéndose lo que está prohibido generalmente (...) mucha mas razon hay para que comprehenda á este género de gente (...) lo que está prohibido a todas las mugeres, no lo han de poder traer las dichas mugeres públicas ni en sus casas ni fuera de ellas; pero lo que á ellas particularmente se las prohibe no se ha de entender dentro de sus casas, sino fuera de ellas, como siempre se ha interpretado y acostumbrado...". Asimismo, otra ley fechada en 1639, prohíbe a las mujeres llevar 'guardainfante' "excepto las mugeres que con licencia de las justicias públicamente son malas de sus personas, y ganan por ello...", igualmente «...se prohibe, que ninguna muger pueda traer jubones que llaman escotados, salvo las mugeres que públicamente ganan con sus cuerpos...». Con anterioridad a esta ley, ya existía otra, fechada en 1575, en que se prohibia a las prostitutas llevar hábitos religiosos, cojín y tapete en las iglesias $^{10}$.

La Pragmática dada por Felipe II en 1565 limita, como se ha visto para Cataluña, el grado de consanguinidad de las personas por las cuales se debe y permite llevar duelo, admitiéndose vestir de luto solamente por los parientes cercanos. Se prohíbe asimismo llevar «loba cerrada ni abierta, sino solamente capas o capuces abiertos o cerrados, excepto por Personas Reales, y marido por muger". A éstas, otra restricción añadida por la ley impone que las mujeres no puedan «traer ni poner tocas de luto negras ni teñidas por ninguna persona que sea, excepto por

${ }^{9}$ Constitucions $i$ altres drets de Catalunya, Libro IX, tit. XXIX, Xi, tit. XXX, LXV. VINYOLEs; "La mujer...", p. 144; y C. BATLLE, L'expansió medieval. Segles XIII-XV, Barcelona, Edicions 62, Col.lecció Història de Catalunyá, vol. III, pp. 406-407.

${ }_{10} \mathrm{~N}$. R., Libro VI, tit. XIII, ley I, V; Libro XII, tit. XXVI, ley VI. 
Personas Reales». De la misma manera, también se prohíbe a las mujeres casadas llevar hábitos ${ }^{11}$.

Al regular cómo se ha de cubrir el cuerpo, las leyes, como parte del cuerpo simbólico de la ideología patriarcal dominante, y en línea con ella, pondrán su énfasis en clasificar a las mujeres entre las que se circunscriben dentro de los límites marcados por el honor y las que traspasan esos límites, es decir, en subrayar la división entre mujeres honestas y deshonestas. Como premio, las mujeres «honorables" mantendrán un rol social subordinado a los hombres pero recibirán a cambio la protección masculina con respecto a la violencia de otros hombres, violencia que para las mujeres "sin honor" constituirá una permanente amenaza. Esta protección, que siempre será relativa, se verá supeditada a un comportamiento de obediencia y subordinación de las mujeres, que deberá además ser recatado, particularmente en el caso de las vírgenes.

\section{LA VIRGINIDAD}

La virginidad ha sido a lo largo de la historia más una construcción social que un referente anatómico o físico. Por ello se ha prestado a múltiples lecturas e interpretaciones. En palabras de Kathleen Kelly la virginidad se construye frecuentemente como sujeto a revisión en el cuerpo que se escribe y revisa según una cultura determinada y que muestra que las identidades corporales son más fluidas que fijas tanto a lo largo de la Historia como dentro de una misma cultura en un periodo determinado. Por otra parte, de acuerdo con Marilyn Frye, etimológicamente la palabra "virgen» en su origen no se refería a la mujer que no había sido penetrada por un hombre, sino a la mujer libre, no prometida, no casada, no ligada a un hombre y que era social y sexualmente ella misma. Fue posteriormente que el concepto adquirió el significado que conocemos. Teniendo todo esto en cuenta, la virginidad puede verse desde diferentes puntos de vista, formando parte de discursos opuestos e incluso antagónicos sobre el cuerpo, y particularmente sobre el cuerpo de las mujeres. Podriamos considerar básicamente dos formas básicas de concebir, vivir o experimentar la virginidad. Una de ellas poco conocida, no ha sido desvelada hasta estudios recientes. Nos referimos a la virginidad como opción consciente, utilizada por las mujeres a lo largo de la historia como un medio para escapar al dominio que iba ligado al deseo de los hombres en la sociedad patriarcal. En este contexto, para Milagros Rivera, la opción de ser virgen podía proporcionar a las mujeres el privilegio de tener un cuerpo inviolable, como sería el caso de Juana de Arco en el siglo xv o de las célibes activas de principios del cristianismo ${ }^{12}$.

1 V. FEFnÁNDEZ y M. V. LÓPEZ-CORDÓN, «Mujer y régimen jurídico en el Antiguo Régimen: una realidad discciada", en Ordenamiento jurídico y realidad social de las mujeres, Actas de las IV Jornadas de investigación Interdisciplinaria, Madrid, Universidad Autónoma de Madrid, 1986, p. 35.

12 M. Rivera Garretas, Textos y espacios de mujeres, Barcelona, Icaria, 1990, pp. 203-206; y J. McNamara, "A. New Song: Celibate Women in the First Three Christian Centuries", en Women and History, 
La otra vertiente de la virginidad, la virginidad ligada al honor y la honra constituye una forma de control de la sexualidad femenina en las sociedades patriarcales y patrilineales. La exigencia de la virginidad a las mujeres va ligada al contrato sexual por el cual los hombres se reparten el poder reproductivo de las mismas, lo cual hace necesario el control de la sexualidad femenina. En otras palabras, la virginidad de las mujeres está ligada a la apropiación de los hijos e hijas, lo cual implica la asunción de la paternidad y la necesidad de asegurarse de esta paternidad. David Bakan basa en este hecho básico de la transición al patriarcado su interpretación del Libro del Génesis. Dicho autor asegura que el tema central del Génesis es que los hombres asumen la paternidad. Cuando los hombres descubren su rol en la concepción comprenden que tienen el poder de procrear que hasta entonces sólo habian atribuido a los dioses. Los hombres, "en su deseo por «legitimar las prerrogativas que parecía que les concedía el gran descubrimiento", aprendieron a distinguir entre "creación" (divina) y "procreación" (masculina). Substituyeron la filiación matrilineal por la patrilineal y, con el objetivo de garantizar la autoridad paterna, exigieron que las mujeres fuesen vírgenes antes del matrimonio y fieles durante el matrimonio ${ }^{13}$.

El control de la sexualidad está estrechamente relacionado con el concepto del honor. El honor reside en los hombres de cada familia, especialmente en el cabeza de familia, pero las mujeres son las depositarias. Una muchacha que pierde la virginidad antes de casarse o ser entregada al hombre al que ha de pertenecer pone en entredicho el honor de los hombres de su familia. Por eso el honor también tiene una relación con el nivel de riqueza. El control de la sexualidad sobre las mujeres nobles y para las burguesas será mucho más estricto que sobre las campesinas debido a la transmisión de riqueza en juego. Por ello, los hombres de los estamentos nobies tendrán más elementos para controlar la sexualidad de las mujeres de su familia que los hombres de los estamentos populares, pues las mujeres pobres se verán abocadas a situaciones más o menos desesperadas por razones económicas que las empujarán hacia la prostitución o hacia relaciones sexuales no protegidas por un próximo matrimonio.

n. ${ }^{\circ}$ 6-7 (1983). El desarrollo reciente en el mundo anglosajón tanto de los estudios de género como de los llamados "queer studies" han dado lugar a un interés renovado por este tema, como se vería en la obra colectiva K. C. KELLY, M. LESLIE (Ed.), Menacing Virgins: Represeniing Virginity in the Middle Ages and Renaissance, London, Associated University Presses, 1999. A pesar de los diferentes significados o las diferentes formas de ver la virginidad, como pasa también en otros temas, cabe plantearse la duda de hasta qué punto estos discursos alternativos se ven o no influenciados por el discurso dominante.

13 Gerda Lerner afirma que la tesis de Bakan coirıcide en algunos puntos con sus propios datos, aunque la encuentra excesivamente determinista y su método ahistórico y subjetivo, ver: D. Bakan, And They Took Themselves Wives: The Emergence of Patriarchy in Western Civilization, Nueva York, Harper \& Row, 1979 y G. LERNER, La creación del patriarcado, Barcelona, Crítica, 1990, pp. 275, 284. Algunos estudios, sobre todo los más recientes, cuestionan el desconocimiento del papel del padre en la concepción en los albores de la humanidad. Según dichos estudios, el parentesco matritineal igualaría al patrilineal en un principio, hasta que la balanza se inclinó a favor de las estructuras patrilineales a partir del desarrollo de la agricultura, particularmente extensiva, y la ganadería. Sin embargo, dicho conocimiento no implicaba que los hombres asumieran y mucho menos necesitaran asegurar dicha paternidad, ver: S. KNO$D E L$, "Unique matrilineal families among the Mosuo", en Orgyn, vol. XIII, n. 4 (2002). También E. BADINTER, L'un est l'autre, Editions Odile Jacob, Le Livre de Poche, 1986, pp. 77-87. 
Precisamente, con el objetivo de resguardar el honor, en la antigua Roma, el padre tenía derecho a matar a la hija que habia perdido la virginidad. Según Eva Cantarella "las fuentes de que disponemos (...) revelan claramente que, entre el amor paterno y la obligación social de salvar el honor perdido a causa del reprobable comportamiento de las hijas, los padres, por lo que parece, escogían el honor'». Por otra parte, en un texto de Livio, éste menciona a dos vestales, una de las cuales había sido acusada de haber perdido su virginidad debido a su forma de vestir, con hermosos vestidos, y a su ingenio. Finalmente la vestal fue encontrada inocente pero se le instó a vestir más modestamente y a reprimir su ingenio. Con respecto a la otra vestal, fue considerada culpable, y la sospecha sobre ella recayó en primer lugar por el ornamento de sus vestidos. También en la tradición judía, de la que el cristianismo es heredero, se relaciona la virginidad y la castidad con la obediencia. Los textos del cristianismo temprano, como los de Ambrosio o Jerónimo, inciden en ello al escribir una semiótica de conducta virginal. Una joven se sabe que es virgen a través de su apariencia, sus vestidos y su conducta, por tanto, que una hija fuese obediente parecía asegurar que su comportamiento sería el apropiado. La obra De Secretis Mulierum, del siglo XIII, considera la conducta modesta como un indicio de virginidad. Como en la época romana o la Edad Media, el Antiguo Régimen es una sociedad que valora mucho la virginidad y la vincula al honor ${ }^{14}$.

Delimitar cuales son los signos que prueban la virginidad ha sido, pues, una preocupación de las ciencias médicas desde la época clásica. Los antiguos griegos creyeron que la calidad de la voz, la anchura del cuello, el flujo de las venas, el tamaño de los pechos, o el color de las mejillas, se veían afectados por la virginidad y su pérdida. Existía una creencia general según la cual la primera relación sexual hacia más profunda la voz de la mujer y alargaba su cuello, como resultado de una respuesta simpatética al estiramiento de su "cuello bajo". Sin embargo, la desfloración como tal no se menciona en el "Corpus hipocrático". A lo largo de los siglos, la existencia del himen, la sangre derivada de su rotura y el dolor durante el primer coito se han valorado como pruebas de virginidad. En De Secretis mulierum, se considera que la ausencia de dolor indica que una mujer no era virgen ${ }^{15}$.

Uno de los "signos" de virginidad más discutidos por doctos hombres de ciencia desde la Antigüedad fue el de la existencia del himen, que aunque fisiológicamente real pusee características variables e inestables. La historiadora australiana Mary Sponberg, que ha estudiado este tema y sus antecedentes históricos para la Inglaterra victoriana, comprueba como el debate entorno a si esta membrana constituye o no una prueba de virginidad, se remonta a tiempos de Hipó-

14 E. Cantarella, La mujer romana, Santiago de Compostela, Universidad de Santiago de Compostela, 1991, pp. 21-24; M. H. Sanchez Ortega, La mujer y la sexualidad en el Antiguo Régimen, Madrid. Akai, 1992, pp. 16 y 100; ANDERSON y ZINSSER, A History of Their Own, pp. 33 y 435; y K. C. KELLY, Performing Virginity and Testing Chastity in the Middle Ages, Nueva York, Routledge, 2000, capitulo 5.

15 M. SPONBERG, "Like a Virgin? The Hymen and Other Myths of Virginity and Their Impact on Nineteenth Century Forensic Science", artículo no publicado, parte de la tesis doctoral de dicha autora. 
crates y continúa hasta fechas recientes. Según esta autora, en la Grecia clásica el himen tenía un significado ambiguo como prueba de virginidad. Aristóteles nunca menciona la existencia de una membrana en la apertura de la vagina, y con respecto al "Corpus hipocrático", tampoco resulta claro si equipara la desfloración con la rotura del himen - como membrana sellada-, o con la pérdida del estoma. Soranus (siglo ॥), sin embargo, pasa por alto cualquier relación del himen con la virginidad $^{16}$.

Con el paso de los siglos, y en concreto durante el período moderno, continuará la misma división de opiniones entre los que consideraran el himen como prueba de virginidad y los que no. Lo cual no impedirá que, a pesar de las diferencias de opinión en el seno de la medicina, en los juicios por violación y otros delitos sexuales se continuará considerando una prueba importante. De hecho, en la Edad Moderna se dio un agitado debate sobre la existencia del himen, que concluyó considerando éste como la señal primaria y más caracteristica de la virginidad, de la cual derivaban todas las demás ${ }^{17}$.

Según Valentina Fernández y María Victoria López-Cordón, en relación con la virginidad y el adulterio aparentemente la Iglesia era más tolerante que la sociedad civil. Afirman que respecto a la virginidad había opiniones contradictorias, pero que, en todo caso, la mujer tenía que decir la verdad porque el matrimonio se consideraba un contrato en que el hombre era el comprador y la mujer la vendedora, y por tanto, el vendedor estaba obligado "en justicia a manifestar el vicio oculto de la cosa vendida" ${ }^{18}$.

A pesar de que a partir del Concilio de Trento la Iglesia estuvo especialmente interesada en reprimir conductas reprobables pero comunes, como por ejemplo la cohabitación, ésta fue una práctica común hasta esas fechas e incluso después, así como el mantenimiento de relaciones sexuales antes del matrimonio, y después de la promesa de matrimonio - promesa que generalmente implicaba cohabitación previa al matrimonio-. Martine Segalen afirma que el código de honor que reside en la joven varía según los lugares, y las normas de conducta son más estrictas en las comunidades más jerarquizadas. Podriamos añadir que también según el nivel de riqueza: a mayor riqueza, más restrictivas las normas, puesto que es mayor la propiedad en juego y mayor también la capacidad de control. Por otro lado, los estudios de Sandra Cavallo y Sandra Cerutti muestran que las formas de control del honor en las zonas en que se acostumbraba a ejercer la cohabitación, consistian esencialmente en el intercambio entre la sexualidad femenina y la palabra de honor masculina, intercambio sancionado con el acto de promesa de matrimonio. Para estas autoras lo que importaba no era la virginidad sino la paternidad y la garantía de que la futura esposa podría tener descendencia. Sin embargo, considero que

16 Ibidem, y J. P. Fontanella, De Pactis Nuptialis sive capitulis matrimonialis tractatus, 1612-1622, cl. 5, gl. 5, p. II, 71-77.

17 Sobre dicho debate, ver: KELLY, Performing..., capítulo 5.

18 Fernández y López-CORdón, “Mujer y ...", p. 32. 
ambos parámetros están en estrecha interrelación, puesto que el futuro marido de la muchacha que está prometida en matrimonio le exigirá que sea virgen ${ }^{19}$.

Aunque la legislación civil catalana y castellana no contempla muy extensamente el tema de la virginidad, las referencias que a ella hace son valiosas y relevantes, confirmando lo escrito hasta ahora. El jurista castellano Alfonso de Acevedo, por ejemplo, denomina propiamente mujer a la que no es virgen, aunque -dice - alguna vez se aluda también a la que es virgen. Afirma que en la ley castellana se toma en su significado más propio, y se denomina mujer a la no virgen, por otro lado el jurista catalán Joan Pere Fontanella denomina a las mujeres no vírgenes, “corrompidas» 20 .

Al analizar la legislación civil catalana con respecto al tema que nos ocupa, cabe destacar la disertación de Fontanella entorno a la comprobación de la virginidad de una mujer. La disertación gira entorno a si se puede comprobar que una mujer es virgen, o lo era, de cara al delito de estupro, y también de cara a los engaños que pueda haber al ser entregada al marido una chica no virgen como si lo fuese.

Fontanella ofrece una definición de virginidad y de lo que es el himen. Citando a Tomás Sánchez afirma que "los antiguos creían que era una piel muy fina que se denominaba himen, la ruptura de la cual constituía la desfloración». Explica que Sánchez, al preguntarse por la señal que indica la virginidad, concluye, según argumentos de médicos muy expertos que «aquella membrana no está hecha de carne, que es denominada himen o engión, sino que en las vírgenes se dice que es peculiar y que marcha herida por la penetración masculina, porque una entre mil no tiene esta membrana». Sin embargo, dice, «hay una casi complicación de las partes del mismo orificio del receptáculo femenino que por la aproximación del hombre se dilatan y así el receptáculo se va abriendo y facilita el paso".

Fontanella explica que para informarse consultó al médico Geroni Llorenç, doctor en medicina, que había escrito una obra en diversos volúmenes sobre historia de la anatomía humana, y en uno de los libros hablaba sobre las partes dedicadas al engendramiento, sobre el himen y los indicios de virginidad. Este médico explica que «entre el pueblo circula el rumor que es una membrana accesible por un pequeño agujero al medio, o (tal como otros creen) perforada por tal que haya un acceso del flujo menstrual, creen que se encuentra en la vagina de la mujer y se rompe con el primer coito y por tanto se rasga" ${ }^{21}$.

Fontanella, refiriéndose a las creencias provenientes de los antiguos comenta: «Así pues, por tal de que la integridad de la virginidad se conociese, creían que se

19 M. Segalen, Mari et femme dans la société paysanne, París, Flammarion, 1980, pp. 26-28; y S. CABALlo y S. CERUTTI, "Onore femminile e controllo sociale della riproduzione in Piemonte tra Sei e Settecento", en Quaderni Storici, núm. 44 (1984).

20 M. J. MuÑoz García, Limitaciones a la capacidad de obrar de la mujer casada: 1505-1975, Madrid, Servicio de Publicaciones de la Universidad de Extremadura, 1991, p. 132; y FonTANELLA, De Pactis, cl. 5 , gl. 5 , p. II, 34 .

21 Fontanclla, De Pactis, cl. 5, gl. 5, p. II, 62-67. 
tenía que averiguar si esta película estaba entera o estaba rota...». El autor critica este argumento y dice que esta película no se encuentra en todas las muchachas, pues hay a quien se les ha desprendido, y no aparece tampoco, según él, en todas las muchachas de la misma manera ni en el mismo sitio. Por tanto, "si en la misma desfloración sucede que sale y se desprende sangre alguna vez, eso pasa por la impetuosa fuerza de quien penetra, que es el primero en abrir lugares cerrados (ya que ciertamente el primer coito es el más doloroso) o por alguna otra causa. Es ridículo si decimos que la película es necesario que se rompa o que hay ciertos vestigios de que ha sido rota de los cuales se deduce que hay indicios ciertos de virginidad íntegra o rota»22.

Para el mencionado autor, éste fue un error que había ocupado la antigua credulidad según la cual la membrana virginal se rompía sólo si había profusión de sangre, por lo cual «muchos y diversos engaños se ingeniaban». Al contrario, opina que "esta sangre no ha de ser mucha, sino más bien poca, tal como lo enseña la experiencia, y por eso, cuando es mucha, es signo de engaño...". De cualquier manera, opina que la tarea de definir el que la membrana se rompa o no en el primer coito es tarea de los médicos, pero “...negamos que no puedan haber signos de virginidad en cualquier mujer, signos por los cuales se puede juzgar si es integra o corrompida....23. Para justificar y demostrar esta idea, el jurista da dos testimonios que considera irrefutables.

El primer testimonio procede de las Sagradas Escrituras, del capítulo 22 del Deuteronomio, quinto libro del Pentateuco. En este capítulo explica el caso de un hombre que recibe a una mujer por esposa, pero le impone un nombre pésimo cuando dice que no la ha encontrado virgen y quiere devolverla a sus padres. Estos se la han de llevar con ellos y revelar los signos de virginidad a los hombres mayores de la ciudad que se encuentran en la puerta, a la vez que se lamentan del yerno diciendo «a éste he dado mi hija que, porque la menosprecia, le impone un nombre pésimo diciendo "no he encontrado a tu hija virgen», y éstos son los signos de mi hija". Entonces, el padre le arranca el vestido a la hija en presencia de los mayores de la ciudad ${ }^{24}$. La dureza y el patetismo de este presunto testimonio es bastante evidente.

El segundo testimonio hace referencia a las matronas y comadronas que son citadas a dar testimonio en favor de las mujeres, y de las que se supone proceden a averiguar los signos de virginidad. Según Fontanella "quién lea todo esto no podrá negar que hay signos de virginidad en la mujer, por los cuales se puede concluir si una mujer es virgen o ha terido contacto carnal. La dificultad sólo radica en distinguir cuáles son estos signos", "...porque todas las mujeres sangran en su primer coito si son vírgenes, y así lo ratifican los doctores...". Comenta que el padre Tomás Sánchez alude a algunos de estos signos de virginidad, para después

22 Ibidem

23 Fontanella, De Pactis, cl. 5, gl. 5, p. II, 62-67, 79.

24 Fontanella, De Pactis, cl. 5, gl. 5, p. II, 71. 
hacer referencia al signo de la sábana manchada, del cual dice que los doctores que tratan de la materia mezclan este signo con otros signos de virginidad de manera indistinta. Sobre este tema explica que en otros lugares existe la costumbre de que los parientes de la novia tomen la sábana donde ésta ha yacido con el hombre durante la primera noche y sea mostrada, manchada, a los padres del hombre $u$ otros parientes en signo de que fue entregada virgen. Afirma que en la ciudad de Barcelona está o habia estado en uso esta observancia entre la gente del pueblo ${ }^{25}$.

La costumbre de enseñar las sábanas con sangre después de la noche de bodas era una práctica secular en los países de la Europa Mediterránea y todavía lo es en paises musulmanes del Norte de Africa y de Oriente Medio. Los supuestos engaños en ésta y otras presuntas pruebas de virginidad fueron también una práctica extendida, como es el caso de la producción de sábanas manchadas, a veces producidas por el mismo novio, con el que la novia habia mantenido relaciones anteriores al matrimonio, o por el hermano, intentando evitar el escándalo y en ambos casos la humillación consiguiente. $O$ bien los casos en que las mujeres fingían dolor o mantenían relaciones sexuales que no implicaban la rotura del himen.

El carácter de la virginidad como una construcción social más que como un factor físico se manifiesta en ciertos casos en los que los expertos se preguntaron sobre si, después de una cierta experiencia, una mujer supuestamente casta era o no era virger. Uno de dichos casos lo presenta Radegunda de Francia, que vivió en el siglo VI y que fue hecha prisionera por Clotario, rey de los francos, que después se casó con ella. Al cabo de seis años y sin hijos, ella huyó y se refugió en la vida conventual, fundando después el monasterio de Santa María, en Poitiers. Después de su muerte se discutió si Radegunda, que después sería beatificada, podia considerarse virgen o no. Por otro lado, uno de los comentaristas de De Secretis Mulierum, se cuestionó si una doncella que aparecía en una historia narrada por Averroes era virgen o no. En dicha historia la muchacha quedó embarazada después de bañarse en agua donde un hombre habia eyaculado ${ }^{26}$.

Diferentes textos revelan, además, una cierta tensión entre la virginidad, la conducta de las vírgenes y la amenaza de la violación. La clausura impuesta a las mujeres -las mujeres honorables no se exponen a la visión pública- se extrema en el caso de las vírgenes. La violación se presenta como una amenaza para la mujer virgen, que puede así dejar de serlo, con la humillación y pérdida de honor consiguiente, al tiempo que dicha mujer virgen, constituiría un premio, bien para el violador, o para el hombre que la poseerá legalmente. Así, según Tertuliano, toda exposición pública de una virgen honesta es para ella como el sufrimiento de la violación. La reforma protestante conforma la idea de la mujer casta, exenta de impulso sexual. Como exponente, Samuel Richardson escribe en 1740 su Pamela,

25 Fontanella, De Pactis, cl. 5, gi. 5, p. Il, 71-78.

26 Rivera Garretas, Textos $y \ldots . .$, pp. 50-55, 206; Kelly, Performing..., capítulo 5. 
mujer virtuosa que gracias a su ejemplo de modestidad y castidad dominará los impulsos sexuales agresivos del hombre ${ }^{27}$. La amenaza de la agresión física contra el cuerpo de las mujeres se erige como disuasivo para mantenerlas dentro de los parámetros delimitados para ellas, es decir, dentro del rol de género. De esta manera podrán ser "protegidas" por los hombres de su familia.

Por ello no es paradójico que ciertas jóvenes vírgenes a las cuales se les suponía "anhelos sexuales" fueran consideradas como no vírgenes. Refiriéndose a ellas, Fontanella comenta la costumbre de otros juristas que excusan de la obligación de tomar por esposa y de dotar al corruptor, cuando la muchacha sobre la cual se ha cometido el estupro y ha sido desflorada, no resulta de vida honesta o es persona vil. El autor se muestra en desacuerdo con el concepto de 'mujer deshonesta' en este caso. Afirma que se entiende por mujer deshonesta la que ha admitido a otros hombres además de quien comete el estupro, y no si solamente yació con éste, aunque lo haya hecho muchas veces, y por tanto no pierde el derecho que marca la ley. Continúa diciendo que «trae dificultad de qué manera puede encontrarse una mujer que conserve la virginidad y lleve una vida deshonesta (...) Si efectivamente es virgen, ¿de qué manera puede ser de vida deshonesta? Y si es deshonesta, ¿de qué manera puede ser virgen?». El autor hace alusión a la ley Julia donde dice que el estupro no es posible que se dé en una virgen meretriz, y agrega "como si fuese posible ser virgen y meretriz a la vez». En esta ley, sigue Fontanella, se menciona a ciertas mujeres de ínfima condición que «vagan por todas partes sin guardar la vergüenza y que no es decoroso para las honestas y de buenas costumbres", y a las mujeres de taberna, sobre las que, dice, no se comete estupro, ni son denominadas viudas, aunque conserven la virginidad, dado que «...¿ ¿no es signo de vida deshonestísima que sea permitido que los huéspedes muy a menudo las besen y las toquen? ${ }^{28}$. El texto de Fontanella no es únicamente contradictorio, sino que, a pesar de que en un principio puede parecer lo contrario, finalmente apoya unos argumentos que permitirían la violación impune de mujeres de baja extracción social.

La legislación contra la violación tenía como objetivo proteger el honor de las familias de las mujeres a través de los cuerpos de éstas. No estaba considerado un crimen contra las mujeres sino un ataque contra la propiedad, contra el control masculino sobre las mujeres de su familia. En un principio se consideraba el robo de la virginidad, que atentaba contra el padre de las doncellas, al provocar que las muchachas perdiesen valor en el mercado matrimonial, e incluso que fuesen rechazadas por su entorno o les fuese imposible casarse. Más adelante se incluyó también a las mujeres no vírgenes. En Cataluña el Usage "Si quis virginem" pre-

27 Sobre la clausura y su función, tanto en el monacato como fuera de él, ver: Rivera GARRETAS, Textos y..., pp. 40-50; y también de la misma autora Nombrar el mundo, p. 103. Tertuliano, De Virginibus Velandis, PL 2,892. Sobre Pamela, de Samuel Richardson, ver: E. LEITES, La invención de la mujer casta, Madrid, Siglo XXI, 1990, pp. 15-19.

28 Fontanella, De Pactis, cl. 5, gl. 5, parte 1, 46-50. Sobre la violación y como las leyes sobre violación se refieren preferentemente a mujeres vírgenes, ver: PÉREZ MOLINA, Las mujeres ante la ley, capítulo 7. 
vee el matrimonio con la víctima o la obligación de dotarla, si ésta es virgen. Si no lo es, sólo contempla lo anterior si como resultado la mujer queda embarazada. Fontanella opina que según el Usage se ha de demostrar que ha habido violencia, y que eso rararnente se puede demostrar si la mujer no es virgen. Argumenta como prueba que los hombres acusados de violación a menudo intentan defenderse por tal de escapar a la pena del Usage arguyendo que la mujer no era virgen. Incluso habla de las pruebas para demostrar que la mujer era virgen, como por ejemplo la sábana manchada de sangre, que, dice, dado los engaños que se dan con esta prueba, sólo sería útil si los violadores son sorprendidos en flagrante delito ${ }^{29}$.

Como se puede observar, las pruebas de virginidad, en distintos períodos y áreas geográficas, tienen en común el haber sido muy indefinidas e intangibles. El propio testimonio de Fontanella, en su diligencia por evitar posibles fraudes, muestra que la virginidad, al menos como es entendida por el discurso dominante, es un tema resbaladizo e ilusorio, que lleva a dudas sobre su verificación. Sin embargo, el autor se muestra contradictorio al asegurar que, a pesar de todo, existen signos o pruebas que determinan si una mujer es o no es virgen. Su discurso, paradigmático del discurso jurídico de la época, se hace eco de la necesidad que tienen los padres y maridos de la Edad Moderna de buscar una forma de asegurar la virginidad de sus hijas y esposas. Esta forma de entender la virginidad se asienta sobre los paradigmas básicos del orden socio-simbólico patriarcal, en que dicha virginidad se entiende como un rasgo específicamente femenino que se inserta en un modelo de sexualidad donde la heterosexualidad es obligatoria. En este contexto se inscribiría también la amenaza de la violación cuando las mujeres, particularmente las vírgenes, no se encuadran dentro de los roles de género impuestos. Por eso el himen, significante, tiene numerosos significados fuera de los puramente físicos y que entran de lleno en el terreno de la construcción social. La construcción de la virginidad como femenina y su pérdida como heterosexual, niega otras posibles experiencias, que de hecho cuestionarían tal paradigma, como la homosexualidad o la virginidad voluntaria antes mencionada.

${ }^{29}$ Constitucions i altres drets de Catalunya, Libro IX, tit. VIII; y I. FontanelLA, De Pactis, cl. 5, gl. 5, parte II, 73, 75-76. Sobre este usage ver también: J. CANCER. Variorum Resolutionum Juris Cesarei Poniifici et municipalis tractatus, 1594-1608, Parte III, cap. II, 46; y L. DE PEGUERA. Decisiones aureae in actu practica frequentes ex varii Sacri Regii Cathaloniae conclusionibus collectae. Barcelona, 1605-1611, cap. $43,1-15$. 